\title{
Culturally Responsive Pedagogy and Academic Vocabulary Teaching and Learning: An Integrated Approach in the Elementary Classroom
}

Hetty Roessingh

Culturally responsive pedagogy (CRP) which provides a general framework for working with culturally and linguistically diverse learners has become the reality in the contemporary elementary classroom in Canada and around the world. This theory-to-practice article presents five research-based teaching practices which make a tangible impact on students' academic vocabulary learning, their academic literacy, and longitudinal educational success. The author illustrates how this vocabulary can be identified, clustered, and contextualized within the frame of a thematic unit. The reader is invited to a classroom in Quebec via a video clip of a dual-language book project that illustrates how principles and practices of CRP can be applied in an FSL setting.

La pédagogie sensible à la culture, fournissant un cadre de travail général quand on travaille avec des apprenants de cultures et de langues diverses, est devenue une réalité dans la salle de classe élémentaire contemporaine au Canada et dans le monde entier. Le présent article, de mise en pratique de la théorie, présente cinq pratiques d'enseignement fondées sur la recherche qui ont un impact tangible sur l'apprentissage du vocabulaire scolaire des élèves, sur leur littératie scolaire et sur leur réussite scolaire à long terme. L'auteur illustre comment on peut identifier ce vocabulaire, le regrouper et le contextualiser dans le cadre d'une unité thématique. Le lecteur est invité dans une salle de classe au Québec grâce à un clip vidéo qui montre un projet de lecture bilingue illustrant comment les principes et les pratiques de la pédagogie qui prend en compte les réalités culturelles peuvent être appliqués dans un contexte de français langue seconde.

Key words: culturally responsive teaching, academic vocabulary, academic literacy, instruction

Over the past 40 years our pedagogical practices have evolved, guided by the ideals of pluralist perspective and the recognition that immigrants bring rich knowledge to their new educational experiences which must be valued and perceived as an asset in the classroom (Volante, DeLuca, \& Klinger, 2019). Drawing on students' linguistic and cultural capital, or funds of knowledge, is a key feature of culturally responsive pedagogy (CRP) (Gay, 
2013; Ladson-Billings, 2014; Moll, Amanti, Neff, \& Gonzalez, 1992). Theorists in this field advocate mobilizing resources including gestures and movement (dance), objects and artefacts, images and artwork, among others, which are representational modes of conveying meaning. These representational modes are inextricably tied to the ways of being and knowing within diverse cultural contexts that offer a potent starting point for second language learning. The broad principles of CRP (Au, 2007; Gay, 2013; Ladson-Billings, 2014; Parhar \& Sensoy, 2011), however, need to be translated into pedagogical practices that align with the principles of second language learning. This gap is addressed in this article.

This theory-to-practice article provides an illustrative example for contextualizing broad principles of CRP that can be applied through a thematically integrated approach to generate literacy learning materials. It underscores the importance of teacher talk and explicit vocabulary teaching and learning in the contemporary elementary classroom. Vocabulary knowledge is particularly regarded as the strongest predictor of reading comprehension and longitudinal educational success (Schleppegrell, 2012).

I begin by providing background information about the learning profile and the needs of the increasing number of Canadian-born children of immigrants. Key features of CRP that link to academic vocabulary development are then described, followed by the elaboration of five strategically selected teaching techniques which consist of embedding direct vocabulary teaching that align with the tenets of CRP. Finally, I present a short video clip that showcases a project where the principles of CRP are highlighted. Trésors de famille (Boyadjieva \& Petreus, 2013) is adapted from a dual language book project described by Roessingh (2011).

\section{The Changing Demographic Landscape in Canada and CRP in the Inclusive Elementary Classroom}

The Canadian elementary classroom is characterized by cultural and linguistic diversity. Many of these children are still in the early stages of developing English language proficiency (ELP) upon entering kindergarten. They have to develop language and literacy skills, and engage with the curriculum demands from the first day of school. They are expected to make the transition to academic literacy with little English language learning support in a few years.

These students are unlikely to develop literacy skills in their first language which is by and large reserved for oral communicative purposes, i.e., to "get things done" within the extended family and first language (L1) community. Thus, their academic literacy must be achieved in English, with little potential recourse to L1 academic language and literacy understandings - crucial in the ability to transfer underlying proficiency to L2 (Cummins, 1979). Data from the Ontario Ministry of Education (Government of Ontario, 2013a) indicate 
that Canadian-born English language learners (ELLs) are underachieving as reflected in the educational outcomes, and the findings are echoed in other jurisdictions across Canada (Alberta Education, 2006) and around the world.

Young ELLs readily acquire basic interpersonal communication skills (BICS) through daily interactions and play with peers (Cummins, 2011; Roessingh, 2018a). This may mask their learning needs to develop academic modes of discourse, and thus many will be overlooked or be unidentified for ESL support. In addition, Canada continues its commitment to resettle those who arrive from refugee backgrounds and seek a second chance in life. For many of them, developing academic literacy will be an enormous challenge.

CRP underscores the importance of exploiting the full measure of diverse students' funds of knowledge (Moll et al., 1992) as resources for teaching effectively. CRP is based on the assumption that when academic knowledge and skills are situated within the students' lived experiences and frames of reference, they are more personally meaningful, have higher appeal, and are learned more easily and thoroughly (Government of Ontario, 2013b).

CRP encourages working with cultural artefacts. Objects provide a concrete touchstone for lower proficiency learners of any age. When these objects have cultural relevance, they are a potent source of direct connection between language and meaning making (Schultz, 2018). Wilson (1999), a neurologist by profession, underscores the importance of haptic information through the hands that establishes the crucial direct neuro connections to the brain, our primary conduit for learning and understanding our world from childhood into the adult years.

Brown (2004) catalogued cultural universals that offer beginning points for connecting concept information, experiences, objects in the material world, and their meanings that are understood across language and culture. Possessions of personal and family value, simple foods such as soups, and personal care such as grooming hair provide a universally accessible and authentic context for making connections through storytelling (another universal), connections that are immediate and personally relevant. More abstract ideas such as leaving home and feelings of loss have also been used to create identity texts (Cummins et al. 2015) which is defined as any type of student-generated text that includes multimodal and digital formats. When students are invited to draw on and contribute these resources to their language learning, teachers demonstrate the importance of the home-school connection, affirm student identity, and reinforce students' sense of agency in their learning journey (Bennett et al., 2017).

Research cited above supports translanguaging, i.e., the use of the learners' full linguistic repertoire across languages in the quest for meaning making (Cummins, 2017; Garcia \& Wei, 2014; Wei, 2018). This suggests not only the need to teach for transfer, but also the recognition that precision of meaning depends on the exact word taken from the L1 repertoire. Thus, for example, in storying Abhi, one of my young students' growing ability 
to groom his own hair (by Sikh tradition, his hair has never been cut), a word such as braid can be translated accurately and readily understood. This serves as a good lesson in language awareness - the explicit and conscious knowledge about language and sensitivity to its use, for both student and teacher (Leonet et al., 2020). Words in Abhi's native Punjabi such as juda, rishi, joora, patka, and rumal emerged spontaneously since there are no equivalent translations of these words. This provides evidence of translanguaging and active bilingualism which marks Abhi as a sophisticated language user; it also allows the opportunity to negotiate meaning and to realize the exact and appropriate word use. This recalibrates the teacher-learner relationship, which is another goal of CRP, i.e., the teacher who is also the learner. I recorded the Punjabi words noted above using a phonics strategy that my young student was able to easily recognize when re-reading the generated text (Roessingh, 2018b). A series of photos Abhi brought along recording the procedure for coiling and securing the rishi provided a good scaffold for this work, which is further supported by my transcription of the co-constructed text. I was able to extend Abhi's vocabulary by inserting more academic words such as manage, connect, process, practice, finally, section, secure, diverse, possession, naturally, cultural, tradition, which represent the "next words to know" for him. In the section that follows, I elaborate on the centrality of academic vocabulary, the need for direct teaching, and I provide five researchbased teaching techniques, followed by an illustration on how they can be embedded in an integrated thematic plan that honours the principles of CPR highlighted in this section.

\section{Teaching and Learning Academic Vocabulary}

There is general consensus in the scholarly community on the centrality of academic vocabulary in the longitudinal educational outcomes of students (DiCerbo et al., 2014; Cummins, 2011; Schleppegrell, 2012). In broad strokes, academic vocabulary is described as the language beyond the "here and now" high-frequency words needed to converse about our daily lives that can be acquired within about two years of exposure to a second language. Academic language must be learned over a protracted period of time and is associated with low-frequency vocabulary, often with Greek and Latin roots. It includes technical and specialized uses of language, words with more abstract meanings, and discipline-specific use of language for curriculum. It is associated with the language of books (Cummins, 2011).

Children initially become literate with a tightly controlled vocabulary of 500-750 high-frequency words, including the 220 function words from the Dolch list (1936), and a few hundred high-interest content words that provide context for learning to decode. Like the vast majority of native English speakers (NES), ELLs accomplish this early literacy feat rather readily, even outperforming their NES peers by Grade 2 (Lesaux \& Siegel, 2003). 
NES, however, will already be well on their way with an oral vocabulary repertoire beyond BICS; they would have learned largely from their parents through turn-taking and "serve and return" conversations that provide rich input (Wallis, 2018), storybook reading, and an array of life experiences afforded to them. Given the central communicative purposes of L1 noted earlier, ELLs may not be exposed to these words at home and are therefore dependent on targeted instructional support from their teachers to develop this level of language proficiency in L2 (Biemiller, 2001; 2003).

There is a significant latency period in the early literacy learning trajectory; however, language learning proceeds at a rapid pace for those advantaged by ways of socioeconomic status (SES) and engaged parents. Those who already possess vast lexical resources can transition from learning to read to reading to learn associated with the Grade 4 year (Chall \& Jacobs, 2003). This is made possible by recognizing print words already extant in the oral repertoire (Biemiller, 2003), and strategy deployment such as contextual guessing and making inferences to get at the meanings of new words. Thus, providing more reading materials to ELLs does not necessarily guarantee comprehension if they do not have the lexical resources to access them; rather, they could fall even farther behind over time since typical early literacy learning materials, whether in reading or writing, comprise of narrative which draw overwhelmingly on high-frequency, conversational language.

New vocabulary is best learned in meaningful contexts within a broad, culturally universal theme such as family treasures, soups, naming traditions (Kapoyannis, 2019) that provides conceptual glue for incremental learning through multiple exposures (Stahl, 2003). When organized into semantic fields or clusters, the potential of incidental linked intake is maximized (Marzano \& Marzano, 1988). Figure 1 illustrates a web of 34 words that might be considered for targeted instruction, depending on the proficiency and age of the students. The approximate grade levels of the words are indicated (Marzano \& Marzano, 1988). The seven blue-coded words have high general academic utility across the curriculum (Coxhead, 2000). The red code indicates topic-specific vocabulary relevant to a unit, Family Treasures which will be explained later. 


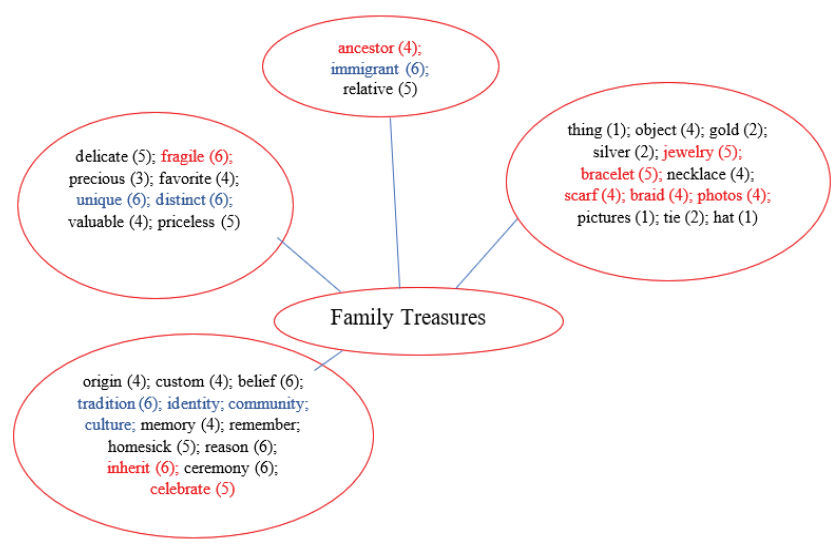

Various types of engagements, deep processing, and recycling are needed for new words to finally become established in the spontaneous productive repertoire of the learners. This involves teaching and providing opportunities to practise, manipulate, and transform words across learning modalities - an approach to planning which reflects a pedagogical intent that aligns with CRP.

Figure 2 displays five research-informed vocabulary teaching strategies identified in the literature that can be applied in the classroom. They follow the principles of second language teaching and learning and CPR which will be further elaborated below.

Figure 2

Five Research-informed Teaching Strategies for Targeting Academic Vocabulary

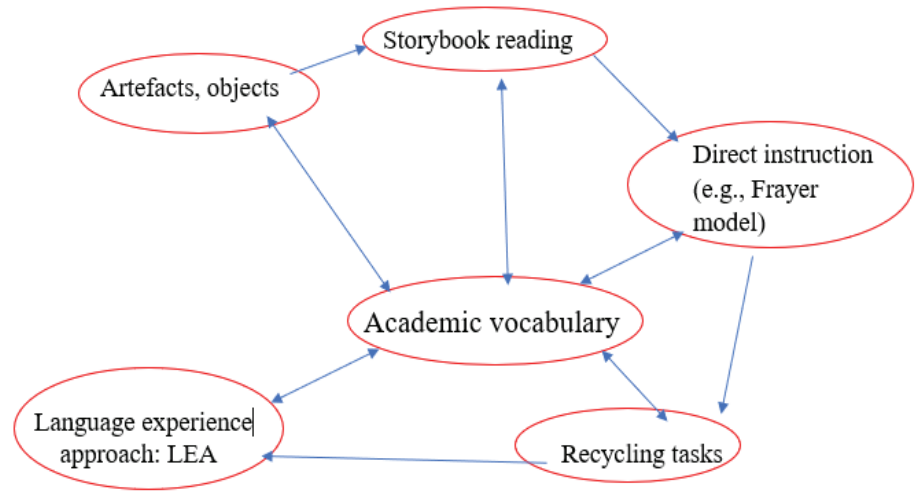


1. Object-based learning. Objects provide an accessible entry point into a thematic plan and make direct connection to new vocabulary. Whether these are cultural artefacts such as prayer beads; personal possessions such as a cup, a tie, or patka; ingredients used in cooking; or name artefacts, objects provide potential for tangible connections to elaborative and collaborative talk.

2. Storybook reading. Many children's books are available in multiple languages, such as Gilman's story Something From Nothing (1992), thus providing opportunities for language awareness and transfer-type teaching practices. A patterned, predictable anchor story for repeated reading allows opportunities to learn and model story grammar, and to provide extra-textual support for introducing new vocabulary (Torr \& Scott, 2006). Dialogic reading uses teacher talk as a pedagogical tool, inviting the back and forth of student engagement (Mercer et al., 2009). Van Kleeck (2008) suggests the opportunity for working on critical thinking strategies through the deliberate introduction of inferential type of questions during storybook reading.

3. Direct instruction. This can involve a technique such as Frayer model (Richardson, n.d.) that helps clarify the properties and set the boundaries of new vocabulary, and provides conceptual information through teacherlead instruction, such as "give an example," "give a non-example," "provide a description," or "generate a definition." Students can also prepare flash cards to keep in their individual word banks (one side of the flash card records the word, the other side with the definition; these can also be translated).

4. Recycling tasks. These can include teacher-prepared crossword puzzles, "working the words" on the flash cards, or any games devised to play with the new words in pairs or with partners. New vocabulary for the class should also be posted in semantic clusters, ideally paired with visual information, on the bulletin board as a permanent external memory support for ongoing use in class and for review.

5. Language experience approach (LEA). Finally, students need productive engagements with language, such as a modified version of LEA (Dorr, 2006). Storytelling and writing impose considerable cognitive load which can be lessened through the use of visual representations and the support of an engaged adult who can transcribe for the learner. Attaching language to cultural artefacts and objects and making the language-literacy connection can follow a process approach to literacy development. In the early stages of literacy learning, especially with young learners, working memory constrains the ability to make meaning and mobilize vocabulary. Prewriting tasks including drawing, sketching, and colouring, afford a concrete touchstone and a priming mechanism for vocabulary to be used in the writing that follows. LEA can be used flexibly by classroom teachers to co-construct students' stories, offering appropriate scaffolding 
and adjusting linguistic input as necessary to align with literacy learning goals and curricular mandates (Roessingh, 2014). Generating LEA texts together provides the ideal reading material for making language-literacy connection with perfect "pitch" which is especially important in Grade 3-4. In my teaching practices with young ELLs, I ensure that the final text generated for student reading and sharing is grammatically correct (and does not contain any spelling errors).

Delpit (1988) reminds us that access to the broader societal opportunity structure afforded to advantaged children can only be made available to "other people's children" if teachers make explicit the language and conventions of academic language which facilitates access to academic modes of discourse. This does not mean denigrating L1 language and culture or asking children to choose between their home language and academic literacy in L2. As noted earlier, this means we must be strategic in exploiting children's full linguistic repertoire, raising their awareness about how languages work in various contexts for various discourse communities, and for various communicative goals. This is how NES should be taught as well.

Figure 3 illustrates a thematic plan that provides context for the strategic integration of the five teaching strategies elaborated above. Family Treasures can be adapted to any age group of students, from kindergarten to high school, to produce identity texts or dual-language books. The progression of lessons is intended to take approximately 15 hours in total; it provides an excellent service-learning opportunity for undergraduate education students. For further details, please visit www.duallanguageproject.com 
Figure 3

Thematic Plan: Family Treasures

Theme Title: Family Treasures: A dual language book project Level: High Beginner - Mid-year Project

Target Group: Any age

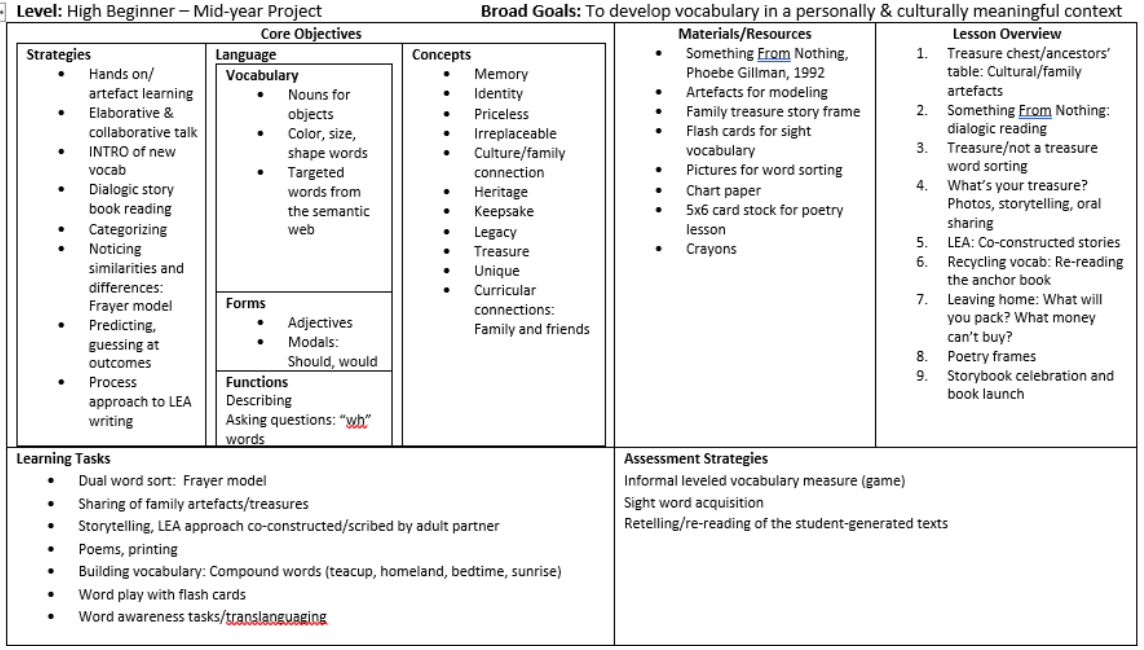

Finally, I invite the reader to join me in a classroom at Louis-Dupire School in Quebec, where children are actively engaged in negotiating meaning, using academic language through talk and print. There is a variety of teacher-lead and explicit teaching, practice opportunity, language-literacy learning, and time to celebrate! Trésors de famille is a dual-language book project that exemplifies many of the teaching practices associated with CRP reviewed in this article; it can have a distinct impact on children's language and literacy learning. Interestingly, building academic proficiency in English can enhance L1 proficiency which may not contain this level of vocabulary knowledge.

\section{Trésors de famille}

Boyadjieva and Petreus, (2013) implemented the principles of CRP in a project that is accessible online: Trésors de famille (http://www.elodil.umontreal.ca/ videos/presentation/video/projet-tresors-de-famille-et-ecriture/).

\section{Conclusion}

Translating theoretical frameworks into classroom practices that will have measurable impact on children's language and literacy achievement is a challenge for the average classroom practitioner. Teachers must go a step further and make the curricular connection that is required of them by government mandate. They are charged with this responsibility in an era 
of conflicting instructional advice, in the context of the inclusive classroom, reaching all children, in a political environment of increased accountability.

The goal of this article is to articulate the principles associated with CRP, to translate these principles into pragmatic approaches for our work in the classroom, and to illustrate how these may be applied flexibly in the classroom to focus on academic vocabulary learning in a balanced approach. This includes both teacher-lead/fronted and student-centered activities. Ready-made, commercially prepared materials such as levelled books, are unlikely to provide the types of personalized, targeted learning described in this article. Visually mediated simulations on a digital screen, animated cartoon-type characters and a disembodied voice emanating from the desktop computer might complement but are no replacement for engaging our students in the analog world with real materials in real time for a real purpose with a real teacher. Wholesale use of authentic materials from newspapers and magazines, likewise, do not provide the comprehensible input and progression ELLs need to develop academic language.

Teachers must be vigilante in monitoring students' changing needs in vocabulary learning; they must provide the types of learning engagements and scaffolded supports to advance literacy development.

\section{Acknowledgement}

Family Treasures was generously supported by TELUS Community projects funding. The project has been implemented in various schools in Calgary including Almadina Language Charter Academy. Their partnership is gratefully acknowledged. I recognize with appreciation the generous contributions of those who reviewed this article and provided excellent feedback that was helpful in the revision process. Finally, the TESL Canada Journal team must be recognized for their contributions in preparing our work for publication and dissemination. Thank you!

\section{The Author}

Hetty Roessingh is a professor in the Werklund School of Education, University of Calgary. Her research interests include early language and literacy learning, longitudinal studies in developing academic literacy, and identifying teaching practices that make a difference to young students' vocabulary learning over time.

\section{References}

Alberta Education. (2006). A review of K-12 ESL education in Alberta. http://www.assembly.ab.ca/ lao/library/egovdocs/2007/aled/158128.pdf

$\mathrm{Au}, \mathrm{K}$. (2007). Culturally responsive instruction: Application to multi-ethnic classrooms. Pedagogies: An International Journal, 2(1), 1-18. https://doi.org/10.1080/15544800701343562

Bennett, S., Gunn, A., Gayle-Evans, G., Barrera, E., \& Leung, C. (2017). Culturally responsive literacy practices in an early childhood community. Early Childhood Education Journal, 46(2), 241- 248. http://doi.org/10.1007/s10643-017-0839-9

Biemiller, A. (2001). Teaching vocabulary: Early, direct and sequential. American Educator, Spring, 2001. http://www.aft.org/newspubs/periodicals/ae/spring2001/biemiller.cfm

Biemiller, A. (2003). Oral comprehension sets the ceiling for reading comprehension. American Educator, spring, 2003. http://www.aft.org/periodical/american-educator/spring-2003/oralcomprehension-sets-ceiling-reading 
Boyadjieva, G., \& Petreus, M. (2013). Trésors de famille. [video] http://www.elodil.umontreal.ca/ videos/presentation/video/projet-tresors-de-famille-et-ecriture/

Brown, D. (2004). Human universals, human nature and human culture. Daedalus, 133(4), 47-54. https://www.jstor.org/stable/20027944

Chall, J., \& Jacobs, V. (2003). Poor children's fourth grade slump. American Educator, Spring, 2003. http://www.aft.org/periodical/american-educator/spring-2003/classic-study-poor-childrensfourth-grade-slump

Coxhead, A. (2000). A new academic word list. TESOL Quarterly, 34(2), 213-238. https://doi. org/10.2307/3587951

Cummins, J. (1979). Linguistic interdependence and the educational development of bilingual children. Review of Educational Research, 49, 222-251. https://doi.org/10.3102/00346543049002222

Cummins, J. (2011). Literacy engagement: Fueling academic growth for English learners. The Reading Teacher, 65(2), 142-146. http://onlinelibrary.wiley.com/doi/10.1002/TRTR.01022/epdf

Cummins, J. (2017). Teaching minoritized students: Are additive approaches legitimate? Harvard Educational Review, 87(3), 404-425. https://hepgjournals.org/doi/pdf/10.17763/1943-504587.3.404

Cummins, J., Hu, S., Markus, P., \& Montero, M. K. (2015). Identity texts and academic achievement: Connecting the dots in multilingual school contexts. TESOL Quarterly, 49(3), $555-581$. https://doi.org/10.1002/tesq.241

Delpit, L. (1988). Power and pedagogy in educating other people's children. Harvard Educational Review, 58(3), 280 - 298. https://doi.org/10.17763/haer.58.3.c43481778r528qw4

DiCerbo, P., Anstrom, K., Baker, L., \& Rivera, C. (2014). A review of the literature on teaching academic language to English language learners. Journal of Educational Research, 84(3) $446-$ 483. http://rer.sagepub.com/content/84/3/446.full.pdf + html

Dolch, E. W, (1936). A basic sight vocabulary. Elementary School Journal, 36(6), 456-460.

Dorr, R. (2006). Something old is new again: Revisiting Language Experience Approach. The Reading Teacher, 60(2), 138-146. https://www.jstor.org/stable/20204444

Garcia, O., \& Wei, L. (2014). Translanguaging: Language, bilingualism and education. Basingstoke: Palgrave Macmillan. https://doi.org/10.1057/9781137385765

Gay, G. (2013). Teaching to and through cultural diversity. Curriculum Inquiry, 43(1), 48-70. https://doi.org/10.1111/curi.12002

Gilman, P. (1992). Something from Nothing. Toronto, ON: Scholastic Canada.

Government of Ontario. (2013a). Capacity Building series 31. Canadian-born English language learners. http://www.edugains.ca/resourcesLNS/Monographs/CapacityBuildingSeries/CBS_ CdnBornELL.pdf

Government of Ontario. (2013b). Capacity Building Series. Culturally responsive pedagogy towards equity and inclusivity in Ontario Schools. Secretariat Special Edition \#35. http://www.edu.gov. on.ca/eng/literacynumeracy/inspire/research/CBS_ResponsivePedagogy.pdf

Kapoyannis, D. (2019). Literacy engagement in multilingual and multicultural learning spaces. TESL Canada Journal, 36(2), 1-25. https://teslcanadajournal.ca/index.php/tesl/article/ view/1329/1155

Ladson-Billings, G. (2014). Culturally relevant pedagogy 2.0: a.k.a. The remix. Harvard Educational Review, 84(1), 74-84. https://doi.org/10.17763/haer.84.1.p2rj131485484751

Leonet, O., Cenoz, J., \& Gorter, D. (2020). Developing morphological awareness across languages: Translanguaging pedagogies in third language acquisition. Language Awareness Journal, 29(1), 41-59. https://doi.org/10.1080/09658416.2019.1688338

Lesaux, N., \& Siegel, L. (2003). The development of reading in children who speak English as a second language. Developmental Psychology, 39(6), 1005-1019. https://pdfs.semanticscholar. org/b0c7/38401bc23cba8f6958dd9a16ad1fc2a76ead.pdf

Marzano, R., \& Marzano, J. (1988). A cluster approach to elementary vocabulary instruction. Newark, DE: International Reading Association. ED293116. https:/eric.ed.gov/?id=ED293116

Mercer, N., Dawes, L., \& Staarman, J. (2009). Dialogic teaching in the elementary science 
classroom. Language and Education, 23(4), 353-369. https://www.tandfonline.com/doi/ full/10.1080/09500780902954273

Moll, L., Amanti, C., Neff, D., \& Gonzalez, N. (1992). Funds of knowledge for teaching: Using a qualitative approach to connect homes and classrooms. Theory into Practice, 31(2). 132-141. http://www.jstor.org/stable/1476399

Parhar, N., \& Sensoy, O. (2011). Culturally responsive pedagogy redux: Canadian teachers' conceptions of their work and challenges. Canadian Journal of Education, 34(2), 189-218. https:// files.eric.ed.gov/fulltext/EJ936750.pdf

Richardson, F. (n.d.). Frayer model. National Behavior Support Service. https://www.nbss.ie/ sites/default/files/publications/frayer_model_-_vocbulary_strategy_handout_copy_3.pdf

Roessingh, H. (2011). Family Treasures: A dual language book project for negotiating language, literacy, culture and identity. Canadian Modern Language Review, 67(1), 123-148. https://doi. org/10.3138/cmlr.67.1.123

Roessingh, H. (2014). Grandma's Soup: Thematic instruction for dual language learners, K-2. Young Children, September, 2014, 86-93. http://www.jstor.org/stable/ycyoungchildren.69.4.86

Roessingh, H. (2018a). Unmasking the early language and literacy needs of ELLs. BC TEAL Journal, 3(1), 22-36. http://ejournals.ok.ubc.ca/index.php/BCTJ/article/view/276

Roessingh, H. (2018b). Listening to our students: THEIR stories. LEARNing Landscapes, 11(2), 287-303. https://www.learninglandscapes.ca/index.php/learnland/issue/view/Teaching\%20 and\%20Learning\%20With\%20Stories/LEARNingLandscapes_vol11no2

Schleppegrell, M. (2012). Academic language in teaching and learning. Elementary School Journal, 112(3), 409-418. http://www.jstor.org/stable/10.1086/663297

Schultz, L. (2018). Object-based learning or learning from objects in the anthropology museum. Review of Education, Pedagogy, and Cultural Studies, 40(4), 282-304. https://doi.org/10.1080/10 714413.2018.1532748

Stahl, K. (2003). How words are learned incrementally over multiple exposures. American Educator, Spring, 2003. https://www.aft.org/periodical/american-educator/spring-2003

Torr, J., \& Scott, C. (2006). Learning 'special words': Technical vocabulary in the talk of adults and preschoolers during shared reading. Journal of Early Childhood Research, 4(2), 153-167. https:// doi.org/10.1177/1476718X06063534

Van Kleeck, A. (2008). Providing pre-school foundations for later reading comprehension: The importance of and ideas for targeting inferencing in storybook shared interventions. Psychology in the Schools, 45(1), 627-643. http://onlinelibrary.wiley.com/doi/10.1002/pits.20314/epdf

Volante, L., DeLuca, C., \& Klinger, D. (2019). The conversation: Culturally responsive teaching in a globalized world. https://www.queensu.ca/gazette/stories/conversation-culturally-responsive-teaching-globalized-world

Wallis, C. (2018). Talking with-not just to-kids powers how they learn language. Scientific American, Feb. 22, 2018. https://www.scientificamerican.com/article/talking-with-mdash-notjust-to-mdash-kids-powers-how-they-learn-language/

Wei, L. (2018). Translanguaging as a practical theory of language. Applied Linguistics, 39 (1), 9-30. https://doi.org/10.1093/applin/amx039

Wilson, F. (1999, October). The real meaning of hands-on education. Waldorf Research Bulletin, 2-12. http://pyrites.org/publications_files/Hands\%20on\%20Education.pdf 